\title{
PELATIHAN DAN PENGEMBANGAN KARIR SERTA PENGARUHNYA TERHADAP PENINGKATAN KINERJA KARYAWAN THE ST. REGIS BALI RESORT
}

\author{
Vania Yuswanto Teja ${ }^{1}$, Adrie Oktavio ${ }^{2 *}$ \\ 1,2 Program Studi Pariwisata, Fakultas Pariwisata, \\ Universitas Ciputra, Surabaya \\ E-mail: ${ }^{2}$ adrie.oktavio@ciputra.ac.id \\ *Penulis korespondensi
}

\begin{abstract}
Abstrak
Di organisasi manapun tidak terkecuali di industri perhotelan, karyawan merupakan aset yang sangat berharga dan seringkali menjadi faktor kunci keberhasilan organisasi. Dengan demikian, setiap organisasi sudah selayaknya menginvestasikan waktu dan sumber daya yang memadai untuk meningkatkan kualitas dan kinerja tenaga kerjanya. Salah satu cara yang cukup efektif untuk memperbaiki kualitas SDM adalah melalui pelatihan. Pelatihan dipandang mampu meningkatkan pengetahuan, keterampilan dan kemampuan karyawan sehingga menjadi lebih mahir. The St. Regis Bali Resort sudah memiliki program-program pelatihan bagi karyawan namun hasil dari pelatihan tersebut jarang sekali untuk dievaluasi ketika karyawan menerapkannya dalam pekerjaan sehingga belum diketahui secara pasti efektifitas dari pelatihan tersebut. Di samping pelatihan, perancangan pengembangan karir juga cukup penting untuk menstimulasi karyawan agar semakin berprestasi dan pada akhirnya juga dapat meningkatkan kinerja karyawan. Penelitian ini berusaha untuk mengamati sejauhmana pengaruh pelatihan dan pengembangan karir dalam meningkatkan kinerja karyawan di salah satu hotel resort bintang lima di Bali. Kuesioner penelitian dirancang menggunakan pernyataan-pernyatan terstruktur dengan tujuan mendapatkan gambaran data persepsi karyawan terhadap variabel-variabel yang diamati dalam penelitian ini. Hasilnya menunjukkan bahwa pelatihan dan pengembangan karir memiliki pengaruh yang positif dan signifikan terhadap kinerja karyawan.
\end{abstract}

Kata kunci: Pelatihan; pengembangan karir; kinerja karyawan; hotel resort.

\begin{abstract}
Any organization, including in the hotel industry, employees are a very valuable asset and are often a key factor in organizational success. Thus, each organization should invest adequate time and resources to improve the quality and performance of them. One of the effective ways to improve the quality of human resources is through training. Training is considered as a tool to improve employees' knowledge, skills and abilities so that they become more proficient. The St. Regis Bali Resort already has training programs for employees but the results of the training are rarely evaluated when employees apply them in work, so the effectiveness of the training is unknown. In addition to training, the design of career development is also quite important to stimulate employees so that they are increasingly performing and ultimately can improve employee performance. This study seeks to observe the extent of the influence of training and career development in improving employee performance in one of the five-star resort hotels in Bali. The research questionnaire was designed using structured statements with the aim of obtaining an overview of employee perception data on the variables observed in this study. The results show that training and career development have a positive and significant impact on employee performance.
\end{abstract}

Keywords: Training; career development; employee performance; resort hotel.

\section{PENDAHULUAN}

Menghadapi tantangan persaingan global seperti sekarang ini, faktor-faktor produksi yang dimiliki oleh sebuah perusahaan biasanya akan dioptimalkan penggunaannya agar dapat mendatangkan keuntungan yang maksimal (Liu, Jiao, Min, \& Yin, 2017). Faktorfaktor produksi tersebut meliputi tenaga kerja, modal, sumber daya fisik, sumber daya informasi dan kewirausahaan (Brynjolfsson \& Hitt, 1995; Hazlitt, 2019; Okpighe, 2015; Xu, Chaudhry, \& Li, 2009). Produksi merupakan sebuah proses kombinasi serta koordinasi dari material-material dan kekuatan termasuk faktor produksi dan sumber daya untuk menghasilkan barang atau jasa sebagai outputnya (Zafirovski, 2002). Untuk mendapatkan hasil yang optimal dibutuhkan sebuah sinkronisasi dari kelima faktor produksi yang harus dimiliki oleh sebuah 
perusahaan (Zafirovski, 2002), sehingga barang atau jasa yang dihasilkan dapat memiliki nilai ekonomis yang dapat mencapai tujuan dari sebuah perusahaan, yaitu memperoleh laba usaha (Liu et al., 2017).

Dalam proses produksi, salah satu faktor terpenting untuk menghasilkan produk (barang atau jasa) adalah tenaga kerja (labor). Produksi serta operasional dalam perusahaan tidak dapat berfungsi dengan baik tanpa adanya manusia (Krajewski, Ritzman, \& Malhotra, 2015; Okoye \& Ezejiofor, 2013). Human Resources Department dalam sebuah perusahaan berfungsi untuk merekrut tenaga kerja yang terlatih untuk mengisi proses produksi sesuai dengan gambaran pekerjaannya serta keterampilannya (Bhaktimayanand, 2010; Okoye \& Ezejiofor, 2013). Karyawan yang memiliki kinerja yang tinggi diperlukan untuk memenuhi salah satu kebutuhan perusahaan, yaitu karyawan yang dapat bekerja lebih baik dan efektif (Locke, 1969; Maślanka-Wieczorek, 2014).

Kinerja (job performance) merupakan salah satu faktor penting bagi setiap tenaga kerja dan perusahaan dalam pencapaian produktivitas (Bakotić, 2016; Ostroff, 1992). Di sisi lain, untuk memenuhi harapan pelanggan, dibutuhkan kinerja karyawan yang memadai dengan cara optimalisasi sumber daya manusia yang dapat dilakukan untuk meningkatkan kualitas dari pelayanan (Mmutle \& Shonhe, 2017; Sharma \& Taneja, 2018). Kinerja karyawan juga didefinisikan sebagai tingkat keberhasilan atau hasil seseorang dalam menyelesaikan tanggung jawabnya dengan kemampuan yang dimilikinya dan pemahaman yang jelas (Lubis, 2008).

Keberhasilan sebuah kinerja tentunya dipengaruhi oleh beberapa aspek seperti pelatihan dan pengembangan bagi karyawan (Bakotić, 2016; Brown \& Sitzmann, 2010; Lubis, 2008; Okoye \& Ezejiofor, 2013; Shaheen, Naqvi, \& Khan, 2013). Pelatihan merupakan sebuah proses sistematis yang merubah tingkah laku karyawan untuk berorientasi pada tujuan organisasi atau perusaahaan (Zahra, Iram, \& Naeem, 2014). Definisi serupa disampaikan oleh Aguinis \& Kraiger (2009) bahwa pelatihan adalah rangkaian aktifitas khusus yang disusun untuk meningkatkan pengetahuan, keterampilan/keahlian, pengalaman, serta berpengaruh terhadap perubahan sikap seseorang. Dari beberapa definisi tersebut dapat ditarik kesimpulan bahwa pelatihan merupakan suatu cara/ tool untuk mengoptimalkan sumber daya manusia (Awan \& Saeed, 2014; Kennedy, 2009). Pelatihan yang diberikan harus termasuk pengalaman belajar, aktivitas yang sudah terencana, serta dibuat sesuai kebutuhan yang telah diidentifikasi agar mencapai sebuah pelatihan yang efektif (Niazi, 2011).
Selain pelatihan, faktor lain yang dapat menunjang kinerja karyawan adalah pengembangan karir, karena pengembangan karir merupakan gabungan dari sebuah perencanaan sumber daya manusia dan pelatihan (Baruch, 2015; Creed \& Hood, 2019). Pengembangan karir adalah proses meningkatkan kemampuan kerja individu yang dapat dicapai untuk mencapai karir yang diharapkan (Barnett \& Bradley, 2007; Baruch, 2015; Triharyanto, 2014), sehingga pengembangan karir dapat menjadi sebuah keuntungan bagi perusahaan dan karyawan (Creed \& Hood, 2019). Dengan adanya pengembangan karir, karyawan memiliki dorongan untuk menyiapkan diri untuk mendapatkan kesempatan karir melalui kinerja dan efisiensi (Davis, 2015; Lee, 2002).

The St. Regis Bali Resort sebagai salah satu luxury resort bintang 5 yang berlokasi di kawasan pariwisata Nusa Dua tentunya harus menjamin kepuasan konsumen, melalui peningkatan atau optimalisasi sumber daya manusia. Oleh sebab itu, The St. Regis Bali Resort berusaha mengoptimalkan kemampuan karyawan mereka melalui sebuah section dalam Human Resources Department yaitu Learning and Development Department untuk memberikan pelatihan terhadap seluruh karyawan serta menjamin pengembangan karir karyawan. The St. Regis Bali Resort yang tergabung dalam Marriott International sendiri mempunyai beberapa program untuk pelatihan dan pengembangan karir karyawan seperti "Marriott Global Sources" dan "Marriott International Career Track" yang menjamin pengembangan karir dan pengetahuan terhadap seluruh karyawannya.

Pelatihan untuk seluruh associates dilaksanakan rutin setiap bulan oleh masing-masing section dan department. Selain itu terdapat pelatihan rutin dari Human Resources Department ataupun dari Marriott pusat secara terjadwal, baik melalui metode online, workshop maupun kelas. Beberapa masalah yang ditemukan terkait dengan pelatihan dan pengembangan karir karyawan tersebut diantaranya tidak ada laporan indikator yang harus dicapai oleh masingmasing karyawan dalam setiap program pelatihan serta evaluasinya. Sehingga pelatihan-pelatihan tersebut terlihat hanya sebatas sebuah "program" yang dilakukan untuk memenuhi permintaan dari Learning \& Development Department ataupun Marriott International.

Seluruh associates The St. Regis Bali Resort juga memiliki Career Track yang terekam langsung oleh Marriott International. Ada sejumlah karyawan yang memiliki karir yang dibangun dari awal yaitu mulai dari menjadi trainee, daily worker, karyawan kontrak, hingga karyawan tetap. Namun demikian, meskipun 
jenjang karir karyawan sudah dirancang sedemikian rupa, ternyata tingkat turnover masih cukup tinggi.

Dari pemaparan di atas, nampak jelas bahwa implementasi program pelatihan dan pengembangan karir masih belum optimal sehingga diduga dapat berdampak pada kinerja karyawan. Oleh karena itu, penelitian ini dilakukan dengan tujuan untuk mengetahui apakah pelatihan dan pengembangan karir yang sudah diterapkan di The St. Regis Bali Resort memang memang berdampak pada kinerja karyawan.

\section{TINJAUAN PUSTAKA}

Kinerja karyawan merupakan buah upaya karyawan dalam melaksanakan tugas dan tanggujawabnya dalam organisasi (Igbaekemen \& Odivwri, 2015). Dengan kata lain, kinerja karyawan merupakan patokan tingkat keberhasilan atau hasil seseorang dalam menyelesaikan tanggung jawabnya dengan kemampuan yang dimilikinya dan pemahaman yang jelas (Lubis, 2008). Kinerja karyawan juga merupakan faktor penting bagi setiap tenaga kerja dan perusahaan bila dikaitkan dengan pencapaian produktivitas (Bakotić, 2016; Ostroff, 1992). Sehingga untuk memenuhi harapan pelanggan, dibutuhkan kinerja karyawan yang memadai dengan cara optimalisasi sumber daya manusia yang dapat dilakukan untuk meningkatkan kualitas dari pelayanan (Mmutle \& Shonhe, 2017; Sharma \& Taneja, 2018).

Keberhasilan kinerja karyawan tentunya dipengaruhi oleh banyak faktor diantaranya pelatihan (Bakotić, 2016; Brown \& Sitzmann, 2010; Lubis, 2008; Okoye \& Ezejiofor, 2013; Shaheen et al., 2013). Aguinis \& Kraiger (2009) menyatakan bahwa pelatihan adalah rangkaian aktifitas khusus yang disusun untuk meningkatkan pengetahuan, keterampilan/ keahlian, pengalaman, serta berpengaruh terhadap perubahan sikap seseorang. Pelatihan juga dipandang sebagai cara/ tool untuk mengoptimalkan sumber daya manusia (Awan \& Saeed, 2014; Kennedy, 2009) sehingga pelatihan yang baik idealnya harus mencakup pengalaman belajar, aktivitas yang sudah terencana, serta dibuat sesuai kebutuhan yang telah diidentifikasi agar efektif (Niazi, 2011).

Selain pelatihan, pengembangan karir juga dapat mempengaruhi kinerja karyawan karena pengembangan karir merupakan gabungan dari sebuah perencanaan sumber daya manusia dan pelatihan (Baruch, 2015; Creed \& Hood, 2019). Karir berkaitan erat dengan pengembangannya, karena pengembangan karir diperlukan dalam implementasi rencana karir seseorang. Pengembangan karir merupakan sebuah proses meningkatkan kemampuan kerja individu yang dapat dicapai untuk mencapai karir yang diharapkan (Barnett
\& Bradley, 2007; Baruch, 2015; Triharyanto, 2014), sehingga pengembangan karir dapat menjadi sebuah keuntungan bagi perusahaan dan karyawan (Creed \& Hood, 2019). Karyawan menjadi terdorong untuk menyiapkan diri untuk mendapatkan kesempatan karir melalui kinerja dan efisiensi (Davis, 2015; Lee, 2002).

\section{Perumusan Hipotesis}

Program pelatihan karyawan didesain sedemikian rupa agar pengetahuan dan keterampilan karyawan dapat ditingkatkan serta mendapatkan pemahaman yang benar dalam sebuah pekerjaan agar lebih efektif dan efisien (Awan \& Saeed, 2014; Niazi, 2011). Bila karyawan memiliki tingkat pengetahuan yang luas, pemahaman akan visi-misi organisasi yang baik serta keterampilan yang mumpuni dalam melakukan tugas dan tanggung jawabnya, maka diharapkan kinerja karyawan semakin baik (Zahra et al., 2014).

$H_{l}$ : Pelatihan mempengaruhi kinerja karyawan secara signifikan

Pengembangan karir adalah bagian penting dalam perjalanan karir seseorang. Usaha perusahaan dalam meningkatkan kemampuan individu yang bertujuan untuk mencapai karir yang diharapkan karyawan merupakan bagian dari proses pengembangan karir (Barnett \& Bradley, 2007; Baruch, 2015). Sehingga dengan adanya pengembangan karir yang jelas dari perusahaan, kinerja karyawan juga akan meningkat. Karena tujuan dari pengembangan karir sendiri adalah untuk memperbaiki serta meningkatkan kinerja karyawan serta efektivitas dalam bekerja untuk dapat mencapai karir yang diinginkan karyawan dan dibutuhkan perusahaan (Davis, 2015; Lee, 2002).

$\mathrm{H}_{2}$ : Pengembangan karir mempengaruhi kinerja karyawan secara signifikan.

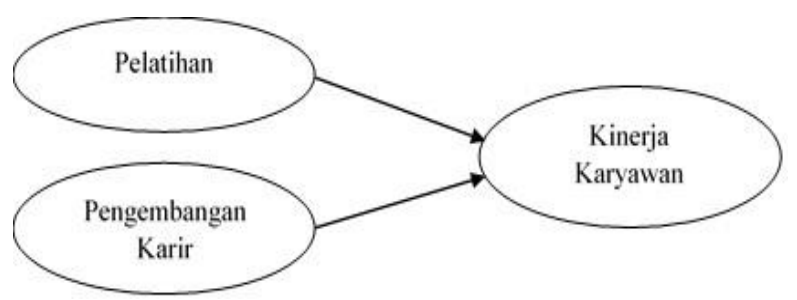

Gambar 1. Model Penelitian

\section{METODE PENELITIAN}

Penelitian ini menggunakan metode ex post facto yang termasuk dalam jenis penelitian kuantitatif dimana penelitian ini meneliti hubungan sebab dan akibat berdasarkan kajian teoritis. Populasi yang diamati dalam penelitian ini adalah seluruh karyawan 
The St. Regis Bali Resort yang berjumlah 373 orang. Dari populasi tersebut, peneliti mengambil sampel sebanyak 100 karyawan berdasarkan penghitungan rumus Slovin. Teknik pengambilan sampel menggunakan simple random sampling. Kriteria sampel adalah merupakan karyawan tetap The St. Regis Bali Resort dengan masa kerja minimal 1 tahun. Instrumen yang digunakan untuk pengumpulan data adalah kuesioner yang disebar pada bulan Maret 2019. Selanjutnya, kuesioner yang sudah terkumpul dan memenuhi kriteria diolah datanya dengan bantuan program SPSS.

Indikator untuk mengukur ketiga variabel penelitian ini semuanya diadopsi dari beberapa penelitian terdahulu. Variabel pelatihan $\left(\mathrm{X}_{1}\right)$ dan kinerja karyawan (Y) mengadopsi 14 indikator pengukuran dari penelitian Lubis (2008). Sedangkan variabel pengembangan karir $\left(\mathrm{X}_{2}\right)$ diukur dengan menggunakan 5 indikator milik penelitian Triharyanto (2014).

\section{HASIL PENELITAN DAN PEMBAHASAN}

\section{Profil Responden}

Total ada 78 responden pria (78\%) dan 22 responden wanita (28\%) yang sudah berpartisipasi. Dari segi usia diketahui bahwa mayoritas responden berusia 31-40 tahun (53\%) dan Sisanya berusia 20-30 tahun (25\%), 41-50 tahun (20\%.) serta 51-60 tahun $(2 \%)$. Berdasarkan kriteria pendidikan, responden berasal dari latar belakang pendidikan Diploma (57\%), SMA/SMK (30\%) dan S1 (13\%). Terkait dengan masa kerja, jumlah responden dengan masa kerja lebih dari 6 tahun sebanyak 71 orang (71\%), 4-6 tahun sebanyak 19 orang (19\%) dan 1-3 tahun sejumlah 9 orang (9\%). Diketahui juga bahwa mayoritas responden berasal dari departemen Food and Beverage Service (23\%), dan secara berturut-turut disusul oleh Housekeeping dan Culinary (22\%); Butler (10\%); Engineering (4\%); Finance, Recreation dan Human Resources (3\%); Loss Prevention, Spa \& Health Club dan Front Office (2\%); serta IT, A\&G, Steward dan Sales Marketing (1\%). Berdasarkan level jabatan, mayoritas responden merupakan staff administrasi dan operasional (54\%) yang berada pada level jabatan 1-3. Disusul kemudian oleh karyawan pada level jabatan 45 yang biasa disebut "lower level management" yaitu supervisor dan assistant manager (32\%), level jabatan 6-7 atau "middle level management" yang diduduki oleh para mananger (12\%), dan karyawan dengan level jabatan 8 -10 atau "top level management" yang diduduki oleh para staf eksekutif seperti Director hingga General Manager (2\%). Dari faktor keikutsertaan karyawan dalam pelatihan, 36 responden
(36\%) mengaku pernah mendapatkan pelatihan setiap bulan sebanyak 1 kali, 25 responden (25\%) mendapatkan pelatihan sebanyak 2 kali dalam sebulan, 8 responden $(8 \%)$ mendapatkan pelatihan sebanyak 3 kali dalam sebulan, 21 responden (21\%) mendapatkan pelatihan sebanyak 4 kali dalam sebulan, 6 responden (6\%) yang tidak rutin mendapatkan pelatihan dan 4 responden lainnya (4\%) mendapatkan pelatihan lebih dari 4 kali dalam sebulan.

\section{Analisis Deskriptif}

Rata-rata jawaban responden terkait dengan indikator-indikator pengukuran dari variabel pelatihan adalah sebesar 4.44 dan termasuk kategori "sangat setuju". Nilai rata-rata yang paling tinggi yaitu 4.67 dari indikator keberhasilan program pelatihan karyawan yang mampu membuat karyawan bekerja lebih mandiri. Sedangkan indikator yang dinilai karyawan paling rendah adalah mengenai keberhasilan program pelatihan yang mampu memupuk tingkah laku positif atau etos kerja karyawan dengan rata-rata sebesar 4.26. Dari hasil tersebut didapatkan gambaran bahwa karyawan sangat setuju jika progam pelatihan dapat meningkatkan pengetahuan serta keterampilan karyawan untuk bekerja lebih baik sesuai standar perusahaan serta mengartikan bahwa program pelatihan yang telah diselenggarakan oleh pihak manajemen sudah sangat baik.

Untuk variabel pengembangan karir, rata-rata jawaban responden secara keseluruhan berada pada angka 4.41 yang masuk dalam kategori "sangat setuju". Nilai rata-rata yang paling tinggi yaitu 4.60 yang ditunjukkan oleh indikator keberhasilan program pengembangan karir melalui pemberian pengetahuan, keahlian dan keterampilan tambahan bagi karyawan. Sebaliknya, indikator yang paling rendah penilaiannya adalah indikator keberhasilan program pengembangan karir melalui perhatian dan bimbingan yang didapat dari rekan kerja serta pemberian kesempatan yang sama bagi semua karyawan untuk mencapai rencana karir yang diharapkan dengan nilai rata-rata sebesar 4.22. Hal ini menunjukkan bahwa perusahaan memberi kesempatan program pengembangan karir kepada karyawan dan program tersebut berjalan sangat baik di The St. Regis Bali Resort.

Persepsi responden terhadap indikator-indikator variabel kinerja karyawan berada pada kategori sangat setuju, dengan rata-rata jawaban responden sebesar 4.54. Nilai rata-rata yang paling tinggi yaitu 4.69 pada indikator ketepatan hasil pekerjaan dalam menyelesaikan tugas dan tanggung jawab sesuai harapan perusahaan. Sedangkan indikator yang dinilai paling rendah adalah mengenai pengetahuan, keterampilan 
dan sikap konstruktif karyawan dalam bekerja bersama dan meningkatkan kinerja dalam sebuah team dengan nilai rata-rata 4.23. Hal ini membuktikan bahwa kinerja karyawan The St. Regis Bali Resort sudah sangat baik dan karyawan sangat setuju jika kinerjanya dipengaruhi oleh pengetahuan dan keterampilan yang didapatkan dari pelatihan dan program pengembangan karir yang diadakan oleh perusahaan.

\section{Validitas dan Reliabilitas}

Untuk mengukur validitas indikator mengacu pada nilai corrected item-total correlation. Jika corrected item-total correlation > r tabel, maka item pernyataan tersebut dinyatakan valid. Nilai $r$ tabel untuk n=100 dan alpha 5\% adalah sebesar 0.197, sehingga apabila nilai corrected item-toal correlation lebih besar dari 0.197 maka item pernyataan tersebut dinyatakan valid seperti yang disajikan dalam Tabel 1.

Tabel 1. Hasil Uji Validitas

\begin{tabular}{|c|c|c|c|c|}
\hline Variabel & Item & $\begin{array}{l}\text { Corrected Item- } \\
\text { Total Correlation }\end{array}$ & $r$ tabel & Keterangan \\
\hline \multirow{6}{*}{ Pelatihan $\left(\mathrm{X}_{1}\right)$} & $\mathrm{X}_{1.1}$ & 0.372 & \multirow{19}{*}{0.197} & \multirow{19}{*}{ Valid } \\
\hline & $\mathrm{X}_{1.2}$ & 0.469 & & \\
\hline & $\mathrm{X}_{1.3}$ & 0.352 & & \\
\hline & $\mathrm{X}_{1.4}$ & 0.519 & & \\
\hline & $\mathrm{X}_{1.5}$ & 0.481 & & \\
\hline & $\mathrm{X}_{1.6}$ & 0.473 & & \\
\hline \multirow{5}{*}{$\begin{array}{l}\text { Pengembang- } \\
\text { an Karir }\left(\mathrm{X}_{2}\right)\end{array}$} & $\mathrm{X}_{2.1}$ & 0.433 & & \\
\hline & $\mathrm{X}_{2.2}$ & 0.494 & & \\
\hline & $\mathrm{X}_{2.3}$ & 0.384 & & \\
\hline & $\mathrm{X}_{2.4}$ & 0.449 & & \\
\hline & $\mathrm{X}_{2.5}$ & 0.479 & & \\
\hline \multirow{8}{*}{$\begin{array}{c}\text { Kinerja } \\
\text { Karyawan (Y) }\end{array}$} & $\mathrm{Y}_{1}$ & 0.662 & & \\
\hline & $\mathrm{Y}_{2}$ & 0.627 & & \\
\hline & $\mathrm{Y}_{3}$ & 0.536 & & \\
\hline & $\mathrm{Y}_{4}$ & 0.509 & & \\
\hline & $\mathrm{Y}_{5}$ & 0.667 & & \\
\hline & $\mathrm{Y}_{6}$ & 0.615 & & \\
\hline & $\mathrm{Y}_{7}$ & 0.722 & & \\
\hline & $\mathrm{Y}_{8}$ & 0.722 & & \\
\hline
\end{tabular}

Pada uji reliabilitas digunakan teknik cronbach's alpha, dengan ketentuan bahwa nilai cronbach's alpha $\geq 0.60$ agar dapat dinyatakan reliabel (Malhotra, 1987). Pada Tabel 2 diketahui bahwa reliabilitas indikatorindikator yang mengukur ketiga variabel penelitian dinyatakan reliabel karena nilai cronbach's alpha $\geq$ 0.60 .

Tabel 2. Hasil Uji Reliabilitas

\begin{tabular}{lcc}
\hline \multicolumn{1}{c}{ Variabel } & $\begin{array}{c}\text { Cronbach's } \\
\text { Alpha }\end{array}$ & Keterangan \\
\hline Pelatihan $\left(\mathrm{X}_{1}\right)$ & 0.707 & \\
Pengembangan Karir $\left(\mathrm{X}_{2}\right)$ & 0.690 & Reliabel \\
Kinerja Karyawan $(\mathrm{Y})$ & 0.869 & \\
\hline
\end{tabular}

\section{Uji Hipotesis dan $\mathbf{R}^{2}$}

Hasil pengujian hipotesis terangkum dalam Tabel 3. Hasil uji hipotesis pertama menghasilkan nilai koefisien regresi sebesar 0.660 dengan nilai signifikansi 0.000. Karena nilai signifikansi lebih kecil dari 5\%, maka dapat disimpulkan bahwa kinerja karyawan dipengaruhi secara positif dan signifikan oleh pelatihan $\left(\mathrm{H}_{1}\right.$ diterima). Selanjutnya untuk hasil hipotesis kedua menghasilkan nilai koefisien regresi sebesar 0.327 dengan nilai signifikansi 0.000 . Karena nilai signifikansi lebih kecil dari 5\%, maka terdapat pengaruh yang positif dan signifikan antara pengembangan karir dan kinerja karyawan $\left(\mathrm{H}_{2}\right.$ diterima).

Tabel 3. Ringkasan Hasil Analisis Regresi

\begin{tabular}{llcccc}
\hline $\begin{array}{l}\text { Variabel } \\
\text { Terikat }\end{array}$ & \multicolumn{1}{c}{$\begin{array}{c}\text { Variabel } \\
\text { Bebas }\end{array}$} & $\begin{array}{c}\text { Koefisien } \\
\text { Regresi }\end{array}$ & $\begin{array}{c}\text { Std. } \\
\text { Error }\end{array}$ & $\begin{array}{c}\text { t } \\
\text { statistik }\end{array}$ & Sig. \\
& Konstanta & 0.176 & 0.320 & 0.549 & 0.584 \\
& Pelatihan $\left(\mathrm{X}_{1}\right)$ & 0.660 & 0.060 & 11.076 & 0.000 \\
Kinerja & Pengembangan & 0.327 & 0.053 & 6.164 & 0.000 \\
Karyawan & Karir $\left(\mathrm{X}_{2}\right)$ & & & & \\
$(\mathrm{Y})$ & R-squared $\left(\mathrm{R}^{2}\right)$ & $=0.664$ & & & \\
& Adjusted $\mathrm{R}^{2}$ & $=0.657$ & & & \\
& F-statistik & $=95.959$ & & & \\
& Sig. F & $=0.000$ & & & \\
\hline
\end{tabular}

Selain dari koefisien regresi dan nilai signifikansi, penulis menggunakan uji $R^{2}$ yang hasilnya sebesar 0.664 , dengan nilai adjusted $R^{2}$ sebesar 0.657 . Artinya, pelatihan $\left(\mathrm{X}_{1}\right)$ bersama-sama dengan pengembangan karir $\left(\mathrm{X}_{2}\right)$ mampu menjelaskan variabel kinerja karyawan (Y) sebesar $66.4 \%$ atau $65.7 \%$. Sisanya (33.6\% atau 34.3\%) dijelaskan oleh variabel lain yang tidak diikutsertakan dalam penelitian ini.

\section{Pembahasan}

Dari hasil uji hipotesis pertama didapatkan hasil yang sesuai dengan hipotesa awal yaitu adanya pengaruh yang positif dan signifikan antara pelatihan dan kinerja karyawan. Hasil penelitian ini selaras dengan beberapa penelitian sebelumnya seperti Awan $\&$ Saeed (2014) dan Shaheen et al. (2013). Beberapa penelitian tersebut semuanya menyatakan bahwa pelatihan merupakan kegiatan yang bertujuan untuk memperbaiki dan mengembangkan tingkah laku, sikap, pengetahuan, serta keterampilan/keahlian karyawan yang sesuai dengan kebutuhan perusahaan. Ketika sikap, tingkah laku, pengetahuan serta keterampilan dapat ditingkatkan, maka secara perlahan-lahan kinerja karyawan juga ikut meningkat (Aguinis \& Kraiger, 2009).

Hipotesa kedua penelitian ini juga dapat dibuktikan bahwa kinerja karyawan dipengaruhi secara positif dan signifikan oleh pengembangan karir. Temuan ini 
juga mendukung penelitian Nadem \& Khawaja (2013) dan Nami Nasution, Mariatin, \& Zahreni (2018). Bila ditinjau dari hasil analisa deskriptif pada variabel pengembangan karir, indikator yang paling rendah menyangkut keberhasilan program pengembangan karir yang didapatkan dari perhatian serta bimbingan dari rekan kerja dan pemberian kesempatan yang sama dalam mencapai karir yang diharapkan oleh karyawan. Hal ini menunjukkan bahwa karyawan masih merasa bahwa kesempatan karyawan untuk mencapai karir yang diinginkan masih belum optimal/merata yang ditemukan oleh peneliti selama masa training mengenai tingkat turnover yang cukup tinggi. Walaupun demikian, rata-rata karyawan masih sangat setuju dengan program-program pengembangan karir yang ada The St. Regis Bali Resort sehingga mereka masih terpacu untuk meningkatkan kinerjanya. Hal ini selaras dengan esensi dari diadakannya program pengembangan karir yaitu untuk memperbaiki serta meningkatkan kinerja karyawan serta efektivitas dalam bekerja untuk dapat mencapai karir yang diinginkan karyawan dan dibutuhkan perusahaan (Davis, 2015; Lee, 2002).

\section{SIMPULAN DAN SARAN}

Kedua hipotesis yang diajukan dalam penelitian dapat diterima dimana adanya pengaruh yang positif dan signifikan antara kedua variabel eksogen yaitu pelatihan maupun pengembangan karir terhadap kinerja karyawan. Hasil penelitian ini juga menemukan bahwa bahwa pelatihan merupakan faktor yang paling berpengaruh dibandingkan pengembangan karir terhadap kinerja karyawan. Sehingga dalam upaya peningkatan kinerja karyawan dibutuhkan pelatihan yang memadai untuk karyawan. Dibutuhkan pelatihan yang sesuai dengan bidang dari masingmasing karyawan serta memperjelas indikator yang harus dicapai dalam sebuah pelatihan. Tujuan utama pelatihan seharusnya adalah untuk membuat karyawan dapat bekerja lebih mandiri dengan pengetahuan serta keterampilan yang diperoleh. Walaupun pelatihan berpengaruh lebih tinggi, tetapi pengembangan karir juga tidak boleh diabaikan begitu saja. Perancangan jenjang karir yang jelas yang dapat dicapai oleh setiap karyawan diharapkan dapat memotivasi karyawan untuk mencapai karir yang diharapkan melalui peningkatan kinerjanya.

\section{DAFTAR REFERENSI}

Aguinis, H., \& Kraiger, K. (2009). Benefits of training and development for individuals and teams, organizations, and society. Annual Review of Psychology, 60(1), 451-474. https://doi.org/10. 1146/annurev.psych.60.110707.163505

Awan, A. G., \& Saeed, F. (2014). Impact of professional training on employees' performance: A case study of Pakistani banking sector. European Journal of Accounting Auditing and Finance Research, 2(8), 70-8.

Bakotić, D. (2016). Relationship between job satisfaction and organisational performance. Economic Research-Ekonomska Istrazivanja, 29(1), 118-130. https://doi.org/10.1080/1331677X. 2016.1163946

Barnett, B. R., \& Bradley, L. (2007). The impact of organisational support for career development on career satisfaction. Career Development International, 12(7), 617-636. https://doi.org/ 10.1108/13620430710834396

Baruch, Y. (2015). Career development: Multilevel perspective. In International Encyclopedia of the Social \& Behavioral Sciences: Second Edition (pp. 128-134). https://doi.org/10.1016/B978-008-097086-8.22003-5

Bhaktimayanand, N. (2010). Recruitment and selection process. Balaji E-Knowledge, 5(4), 1-32.

Brown, K. G., \& Sitzmann, T. (2010). Training and employee development for improved performance. In APA handbook of industrial and organizational psychology, Vol 2: Selecting and developing members for the organization. ( $\mathrm{pp}$. 469-503). https://doi.org/10.1037/12170-016

Brynjolfsson, E., \& Hitt, L. (1995). Information technology as a factor of production: The role of differences among firms. Economics of Innovation and New Technology, 3(3-4), 183-200. https://doi.org/10.1080/10438599500000002

Creed, P., \& Hood, M. (2019). Career development, planning, and management from the organisational perspective. In Vocational Psychological and Organisational Perspectives on Career (pp. 39-62). https://doi.org/10.1163/97890879091 78_005

Davis, P. J. (2015). Implementing an employee careerdevelopment strategy: How to build commitment and retain employees. Human Resource Management International Digest, 23(4), 28-32. https://doi.org/10.1108/HRMID-05-2015-0066

Hazlitt, H. (2019). Economics in one lesson. In American Conservative Thought in the Twentieth Century (pp. 144-189). https://doi.org/10.4324/ 9781315082677-9

Igbaekemen, G., \& Odivwri, J. (2015). Impact of leadership style on organization performance: A 
critical literature review. Arabian Journal of Business and Management Review, 5(5). https://doi.org/10.4172/2223-5833.1000142

Kennedy, J. (2009). The impact of training and development on job performance. Singapolean Journal of Business Economics, and Management Studies, 6, 65-71. Retrieved from http://dspace.knust.edu.gh:8080/jspui/bitstream/ 123456789/593/1/JOSEPH KENNEDY.pdf

Krajewski, L. J., Ritzman, L. P., \& Malhotra, M. K. (2015). Operations management: Processes and supply chains. Operations Management (11th ed.). Pearson Education. https://doi.org/10. $15358 / 9783800644858$

Lee, P. C. B. (2002). Career goals and career management strategy among information technology professionals. Career Development International, 7(1), 6-13. https://doi.org/10.1108/136204 30210414829

Liu, S., Jiao, W., Min, Q., \& Yin, J. (2017). The influences of production factors with profit on agricultural heritage systems: A case study of the rice-fish system. Sustainability (Switzerland), 9(10). https://doi.org/10.3390/su9101842

Locke, E. A. (1969). What is job satisfaction? Organizational Behavior and Human Performance, 4(4), 309-336. https://doi.org/10.1016/00305073(69)90013-0

Lubis, K. A. (2008). Pengaruh pelatihan dan motivasi kerja terhadap kinerja karyawan PT Perkebunan Nusantara IV (Persero) Medan. Universitas Sumatera Utara. https://doi.org/10.1016/j.fuel. 2011.01.009

Malhotra, N. K. (1987). Validity and structural reliability of multidimensional scaling. Journal of Marketing Research, 24(2), 164. https://doi.org/ $10.2307 / 3151506$

Maślanka-Wieczorek, B. (2014). Talent management and high performance work system. Journal of International Studies, 7(1), 102-108. https://doi. org/10.14254/2071-8330.2014/7-1/9

Mmutle, T., \& Shonhe, L. (2017). Customers' perception of service quality and its impact on reputation in the hospitality industry. African Journal of Hospitality, Tourism and Leisure, 6(3).

Nadeem, A. B., \& Khawaja, J. (2013). Training and development program and its benefits to employee and organization: An conceptual study. European Journal of Business and Management, 5(2), 243-252.

Nami Nasution, F., Mariatin, E., \& Zahreni, S. (2018). The influence of career development and organizational culture on employee performance. International Journal of Scientific Research and Management, 6(01). https://doi.org/10.18535/ ijsrm/v6il.el09

Niazi, B. A. S. (2011). Training and development atrategy and its role in organizational performance. Journal of Public Administration and Governance, 1(2), 42. https://doi.org/10.5296/ jpag.vli2.862

Okoye, P. V. C., \& Ezejiofor, R. A. (2013). The effect of human resources development on organizational productivity. International Journal of Academic Research in Business and Social Sciences, 3(10). https://doi.org/10.6007/ijarbss/ v3-i10/295

Okpighe, S. (2015). The seven factors of production. British Journal of Applied Science \& Technology, 5(3), 217-232. https://doi.org/10.9734/bjast/ 2015/12080

Ostroff, C. (1992). The relationship between satisfaction, attitudes, and performance: An organizational level analysis. Journal of Applied Psychology, 77(6), 963-974. https://doi.org/10.1037/00219010.77.6.963

Shaheen, A., Naqvi, S. M. H., \& Khan, M. A. (2013). Employees training and organizational performance: Mediation by employees performance. Interdisciplinary Journal of Contemporary Research in Business, 5(4), 490-503.

Sharma, S., \& Taneja, M. (2018). The effect of training on employee performance. International Journal of Recent Technology and Engineering. https://doi.org/10.31104/jsab.v2i2.49

Triharyanto, H. (2014). Pengaruh pelatihan dan motivasi kerja terhadap pengembangan karir awak kapal pengawas perikanan pada Ditjen Pengawasan Sumber Daya Kelautan dan Perikanan (PSDKP). Universitas Terbuka. Retrieved from http://repository.ut.ac.id/1149/1/40791.pdf

Xu, B., Chaudhry, S. S., \& Li, Y. (2009). Factors of production: Historical theories and new developments. Systems Research and Behavioral Science, 26(2), 219-224. https://doi.org/10.1002/ sres. 972

Zafirovski, M. (2002). The social construction of production: An application of economic sociology. Management. https://doi.org/10.3917/ mana.052.0147

Zahra, S., Iram, A., \& Naeem, H. (2014). Employee training and its effect on employees' job motivation and commitment: Developing and proposing a conceptual model. IOSR Journal of Business and Management, 16(9), 60-68. https://doi.org/10.9790/487x-16916068. 